\title{
Frontera y Estado feudal en Aragón y Cataluña durante el siglo XII
}

\author{
Carlos Laliena Corbera \\ Departamento de Historia Medieval, Facultad de Filosofía y Letras, Universidad de Zaragoza, Zaragoza, \\ España
}

The main hypothesis of this paper states that the frontier does not constitute a structural feature of the Iberian societies in the twelfth century. Conversely, it results from a time-limited process, and thereby traditional ideas according to which the frontier was a physical and social space where a particular society was created and long-term cultural exchanges took place are wrong and based on a historiographical assumption rather than verified evidence. This work develops the argument that growing feudal states could not tolerate fluid and extended borders in social and temporal terms. This was the case in the Ebro Valley and its Iberian edges. Between 1080 and 1130, the conquest destroys the foundations of the taifa sultanates, and disrupts the Andalusian society. Thereupon, between 1150 and 1190, the Catalanaragonese sovereigns impose in border territories, and their aristocratic competitors miss the opportunity to begin the thirteenth century consolidating big autonomous or semiautonomous domains, with the relative exception of Albarracin. This paper studies the way in which this entrenchment of the Catalan-aragonese state took place and impeded the consolidation of a "border society".

\section{ARTICLE HISTORY}

Received 13 July 2018

Accepted 19 October 2018

\section{KEYWORDS}

Crown of Aragon; Catalina; Kingdom of Aragon; medieval frontier; feudal State; al-Andalus; mudéjares; military orders

\section{Introducción}

La frontera es una metonimia del Estado. No existen estados sin fronteras, ni, por supuesto, fronteras que carezcan de un estado que las cree. Esta afirmación puede parecer una tautología si la examinamos desde la perspectiva de los siglos bajomedievales y modernos, pero, para periodos anteriores, debemos tener en cuenta que la experiencia de los antropólogos constata a contrario que los grupos étnicos fijan límites entre ellos que no son necesariamente territoriales. Fredrik Barth, en particular, subraya que las delimitaciones que los separan son de naturaleza cultural y hacen que la pertenencia étnica sea una cuestión de estrategias individuales o colectivas y carezca del contenido institucional que resulta de la existencia de las fronteras entre estados. ${ }^{1}$ James Scott sugiere que hubo grupos étnicos que fueron capaces de eludir su captura dentro del radio de acción de los estados precoloniales y coloniales en las tierras altas del sudeste asiático, antes de sucumbir ante el avance de los estados actuales. ${ }^{2}$ Con todo, estas experiencias muestran que, en líneas generales, puede defenderse el argumento que vincula el desarrollo del

CONTACT Carlos Laliena Corbera claliena@unizar.es

"Barth, "Introducción," 9-48.

${ }^{2} \mathrm{~S}$ cott, Art of Not Being Governed.

(c) 2018 Informa UK Limited, trading as Taylor \& Francis Group 
Estado y el establecimiento de fronteras y que solo la debilidad estatal permite la persistencia de los fenómenos sociales señalados por estos investigadores. Se trata de una idea que cuenta con una significativa tradición historiográfica, ${ }^{3}$ aunque quizá pasa un poco desapercibida en una vasta bibliografía medievalista sobre el tema de la frontera, que reviste sobre todo un carácter cultural o sociológico: la frontera concebida como un espacio de contactos e intercambios; la frontera vista como el ámbito de una sociedad específica. ${ }^{4}$ Con frecuencia, la noción de frontera se convierte en un elemento que, a juicio de los historiadores, unifica la evolución de sociedades enteras a lo largo del tiempo. ${ }^{5}$ Por supuesto, la larga expansión de los principados cristianos en la Península Ibérica ha sido campo abonado para la aplicación de estas concepciones y ha generado una poderosa interpretación del pasado hispánico que, a su vez, ha dado lugar a numerosos comentarios ${ }^{6}$ y ha sido revitalizada por los hispanistas. ${ }^{7}$

La tesis que propongo aquí se desmarca de los planteamientos tradicionales en torno a las fronteras ibéricas medievales ${ }^{8}$-fronteras laxas, regionales, religiosas, culturales, espacios donde emergen formas sociales diferentes, donde tienen lugar procesos de aculturación e interacción- para subrayar que en ellas todos esos elementos tuvieron una vida corta, determinada por la aceleración de la dinámica del Estado feudal que, en última instancia, condujo a la creación de fronteras lineales que, al mismo tiempo, fueron menos relevantes como elemento organizador de las sociedades feudales articuladas por este tipo de estados de lo que se suele admitir. ${ }^{9}$

Esta idea es el corolario de una definición del Estado basada en el monopolio legítimo de la violencia física y simbólica ejercida por una organización o conjunto de instituciones en un espacio bien definido, que reclama centralidad y reviste un cierto grado de autonomía con respecto a los intereses de clase. ${ }^{10}$ La configuración de un estado determina la aparición de una frontera puesto que, si carece de ella, es decir, de un territorio bien

\footnotetext{
${ }^{3}$ Sahlins, Boundaries; Power, "Frontiers," 1-13; Ladero Quesada, "Evolución de las fronteras," 5-49; Guinot Rodríguez, Limits del regne; Power, Norman Frontier; Sabaté, "Changement de frontières," 21-62.

"Berend, "Medievalists," 55-72. Castrum 4; Abulafia y Berend, Medieval Frontiers; Bartlett y MacKay, Medieval frontier societies; Ayala, Buresi y Josserand, Identidad y representación; Las sociedades de frontera, sobre esta perspectiva.

${ }^{5}$ El concepto de frontera es utilizado a escala europea por Bartlett, Formación de Europa; Murray, Clash of Cultures, sobre el Báltico y las fronteras orientales de la Cristiandad; Lieberman, Medieval March of Wales, sobre Gales (que, con Escocia e Irlanda, son terreno de predilección de los estudios sobre sociedades de frontera medievales); Power, Norman Frontier sobre un espacio feudal característico; en general, véase también Power y Standen, Frontiers; Curta, Borders. MacKay, España, es la obra clásica sobre el mundo hispánico.

${ }^{6}$ Torró, "Viure del botí," 5-32; Sabaté, "Frontera peninsular," 44-97.

${ }^{7}$ Buresi, Frontière, 14-15; Sénac, Frontière et les hommes; Menjot, Murcie.

${ }^{8}$ Obviamente, "tradicionales" no equivale a erróneos, pero sí a concepciones que respetan una "gran narrativa" sobre la Edad Media hispánica que arranca de los trabajos de Charles J. Bishko, "Castilian," (edición original, 1963); Jean Gautier-Dalché, "Islam," 183-217; y José María Lacarra, "Villes-frontière," 205-22. Estas obras, citadas infinidad de veces, impregnan buena parte de la historiografía medievalista española, junto con obras posteriores como Reyna Pastor de Togneri, Islam; Robert I. Burns, Crusader; Michel Zimmermann, "Rôle", 7-29; Manuel González Jiménez, "Frontier," 49-74. Una versión actualizada y enriquecida: Sabaté, "Frontière catalane," 185-218.

${ }^{9}$ La hipótesis dominante es que las fronteras lineales se desarrollan a partir del siglo XIII o incluso del XIV, como parte de la formación de estados más avanzados. Como muestra P. Sahlins, incluso fronteras establecidas por comisiones apropiadas y cartografiadas, como la de Cerdanya desde mediados del siglo XVI, eran poco precisas —-Sahlins, Boundaries, 61-102-, pero, teniendo estas reservas en cuenta, creo que la argumentación que desarrollaré permite afirmar que las fronteras eran razonablemente lineales incluso en la segunda mitad del siglo XI. De hecho, varios de los aspectos que señala este autor en el proceso de formación de la frontera en la Cerdanya pueden observarse mucho antes: Tomás Faci, "Derecho y fiscalidad," 615-38. También Sabaté i Curull, Territori, 281-313, Ladero Quesada, "Evolución de las fronteras"; o Martínez Sopena, "Villas del rey," 105-44. Mi propósito contrasta con la perspectiva de Flocel Sabaté, para quien la frontera se convierte en "un eje central que explicará la evolución específica del noreste de la Península Ibérica": Frontière catalane, 189.

${ }^{10}$ Weber, Economía y sociedad, 45; Bourdieu, Sobre el Estado, 14. Mann, Fuentes del poder social, 64, resalta la centralidad
} como un componente esencial de la definición del Estado. 
establecido sobre el que aplicar la dominación, no es un estado, es otra cosa. Y la existencia de clases y de estructuras de dominación, que es inherente a sociedades como las que existían a partir del año mil - si no antes- en las unidades políticas que solemos calificar de reinos o condados en el norte peninsular, induce a pensar que eran estados o evolucionaban con rapidez para serlo. ${ }^{11}$

La construcción de una frontera implica la eliminación de las posibilidades étnicas, sociales y culturales alternativas, es decir, las propias de aquellos colectivos y elites para los cuales los territorios periféricos del Estado en vías de formación eran el campo propicio para desarrollar pautas culturales diferentes y modelos de autoridad o autonomía que escapaban al poder centralizador de naturaleza estatal. Y, por supuesto, suponían la desintegración en mayor o menor grado de cualesquiera grupos étnicos que pudieran mantener algún grado de cohesión en tales territorios. El objetivo no era solo imponer los sistemas de extracción del excedente y de control social propios de la clase aristocrática feudal, sino también conseguir que en ningún caso las formas concretas de estos sistemas fuesen concurrentes con el Estado.

En una formulación clarividente, Pierre Toubert declaraba que "la zona fronteriza es, por esencia, una región de sobreinversión de poder público" que tiende a afectar a todos los componentes del cuadro social: fortificaciones, poblamiento, mercados, desarrollo urbano, inmigración, franquicias y nuevos paisajes. ${ }^{12}$ Al tutelar estas transformaciones, el Estado y sus instituciones se revestían de una legitimidad adicional que no derivaba solamente de su capacidad de redistribuir riqueza entre los miembros de la aristocracia feudal y de cumplir funciones simbólicas y litúrgicas, como antaño, sino que provenía también de una relación nueva con los súbditos caracterizada por las nociones de protección, organización, ley y, hasta cierto punto, identidad compartida. La desaparición de la frontera como una entidad zonal y su conversión en un límite bien establecido era la condición necesaria para la consolidación del Estado feudal y, en el Valle del Ebro, este proceso tuvo lugar entre 1080 y 1200 en dos fases distintas. Durante la primera, los musulmanes que vivían en los espacios limítrofes con el reino navarroaragonés y los condados catalanes fueron sometidos a una intensa depredación que liquidó su existencia como un grupo étnico en el sentido en que Fredrik Barth califica a estos conjuntos sociales, un grupo que, además, contaba en origen con el respaldo de una estructura estatal propia. En la segunda etapa, Alfonso II y Pedro II pulverizaron las posibilidades de que el Aragón y la Cataluña meridionales pudieran convertirse en una tierra de nobles semiindependientes y dar, de este modo, un carácter particular a las regiones conquistadas. Este trabajo pretende examinar estos dos procesos. Para ello, la primera parte explicará la forma en que las sociedades islámicas de Zaragoza, Lleida y Tortosa fueron brutalmente

\footnotetext{
11 "Estado feudal" no es un sinónimo de "monarquía feudal" o "reino". Por la primera de estas expresiones, que me parece mucho más rigurosa desde la perspectiva de la ciencia social actual, entiendo una forma específica de dominación que debe cumplir algunos requisitos: una dinastía y una política dinástica que articulase un poder todavía muy personalizado; itinerancia de los dirigentes; asambleas; cierto grado de centralidad política expresado a través de un control más o menos eficaz de los recursos materiales y simbólicos — un patrimonio fiscal, acuñación de moneda, ejercicio de la justicia y tutela de la Iglesia-; y una ordenación de la clase aristocrática basada en los vínculos feudovasalláticos — fidelidad, homenajes y feudos - Desde esta perspectiva, no solo los reinos como Castilla-León, Pamplona-Navarra o Aragón eran estados feudales, sino que también condados como Barcelona y Urgell pueden ser calificados como tales, por no mencionar a los condados y vizcondados del sur de Francia, en esta época estrechamente relacionados con el norte de la Península Ibérica. Como es obvio, pocos estados feudales desembocaron en estados-nación modernos y contemporáneos, de manera que establecer cualquier relación en este sentido es un anacronismo.

${ }^{12}$ Toubert, "Frontière," 13-14.
} 
castigadas hasta que sus aparatos políticos se desintegraron y los marcos sociales que las sostenían claudicaron. La segunda analizará la tentativa de la elite feudal para construir núcleos de poder semiautónomos, en la línea de lo que era habitual en la Europa mediterránea de la época, mientras que la tercera pondrá en evidencia las estrategias desplegadas por los soberanos de la Corona de Aragón para anular esas pretensiones y las dimensiones de su éxito.

\section{La destrucción del islam del Valle del Ebro: frontera y depredación}

Un documento aragonés de abril de 1083 describe con claridad los fenómenos que estaban teniendo lugar en las fronteras a finales del siglo XI. ${ }^{13}$ En esa fecha, Sancho Ramírez y sus nobles se apoderaron de Ayerbe, una fortificación islámica sobre el curso del río Gállego que limitaba el acceso de los aragoneses a las planicies del Ebro que rodean a Huesca y Zaragoza. El texto proporciona una amplia información sobre el modo en que se organizó el reparto de los beneficios derivados de la conquista de esta localidad y la ideología que subyacía en esa distribución. El rey concedió la mitad de los ingresos reales procedentes de una renta denominada la "novena" que pagaban los inmigrantes instalados en ella a "los seniores para la custodia y defensa de esa fortaleza (castrum) y de toda la patria". Con la misma finalidad, les dio la mitad de los tributos que pagaban los musulmanes de doce lugares situados a lo largo del río Flumen, al sur de Huesca. De la parte que el soberano había retenido, tanto de las rentas como de las parias, cedió la mitad - es decir, una cuarta parte del total - al monasterio de San Juan de la Peña junto con una iglesia en la capital oscense para que

Dios omnipotente, aplacado por las oraciones de san Juan Bautista y de todos sus santos, contemple la aflicción de su pueblo redimido por su preciosa sangre y, apiadándose de nosotros, en el futuro nos dé la ciudad de Huesca, como creemos confiados [que lo hará].

Los dos pilares del poder, los magnates y la Iglesia, estaban representados en esta distribución de las riquezas inherente a las posibilidades que ofrecía la ocupación de Ayerbe, y, con ellos, las respectivas ideologías que legitimaban la conquista: el honor feudal y las donaciones piadosas.

La palabra que emplea el documento y que he traducido como "tributos" o "parias" es almudegana, del árabe andalusí mudájjan, "sometido", que, por extensión, se refiere a "lo que pagaban los sometidos". ${ }^{14}$ En 1049, Ramiro I explicó en otra carta en favor del monasterio de San Victorián de Sobrarbe el contenido de estos pagos efectuados por las poblaciones andalusíes que tenían la desgracia de hallarse cerca de las fortificaciones cristianas: "grano, vino, oro, plata, telas y calzado" ${ }^{15} \mathrm{Nada}$ indica que el resultado del saqueo sistemático de esta hilera de lugares escalonados al sur de Huesca fuese diferente de esta modalidad de botín.

Entre 1086 y 1089, Sancho Ramírez construyó un importante castillo en las inmediaciones de Huesca, sede a la vez de un honor y de una capilla real con un capítulo agustiniano, al que dotó, entre otros bienes, con iglesias que habían sido erigidas en decenas de aldeas del antiguo distrito musulmán de Huesca - "entre el río Alcanadre y el río Gállego",

\footnotetext{
${ }^{13}$ DSRI. no 21. Laliena Corbera, "Regis fevales," 499-514; Laliena Corbera, Formación del Estado feudal.

${ }^{14}$ Corriente, Diccionario de arabismos, s.v. "mudéjar".

${ }^{15}$ CDMSVS. $n^{\circ} 24$. En este caso, la donación correspondía a las "almotexenas" de las comarcas del Sobrarbe.
} 
reza el documento- o que se esperaba que lo fuesen en un periodo inmediato, así como con el diezmo de la almutegena que satisfacían los campesinos musulmanes de esta comarca. ${ }^{16}$ Una de las copias de esta pieza, que presenta múltiples evidencias de haber sido manipulada, incluye entre las posesiones que obtenía la abadía diversas mezquitas rurales y los alchobcis sarracenorum, una expresión que procede del árabe hubs (pl. ahbas), "bienes pertenecientes a las mezquitas producto de legados píos". ${ }^{17}$ Los arreglos introducidos en la copia no eliminan la verosimilitud de estas indicaciones, que manejan un vocabulario que cayó muy pronto en el olvido. Por el contrario, es muy probable que las propiedades de las mezquitas fueran objeto principal de la ambición de la clase aristocrática y eclesiástica aragonesa. Así pues, los tributos de los musulmanes y las modestas riquezas que atesoraban las mezquitas rurales constituyeron la primera y más directa ganancia de una auténtica fase de rapiña, más que de una conquista, una depredación que en absoluto fue caótica y azarosa, sino que fue planificada y coherente. ${ }^{18}$

Por poco tiempo, sin embargo. En 1100, Pedro I entregó a San Juan de la Peña la cuarta parte de las doce poblaciones que diecisiete años antes su padre había donado a los monjes en lugar de la parte de los tributos que les correspondía. ${ }^{19}$ La explicación de este cambio de los ingresos obtenidos a través de las parias por la posesión alodial de un dominio señorial radica en la rápida pérdida de habitantes de estas localidades, solo en parte sustituidos por campesinos aragoneses. ${ }^{20}$ De hecho, al menos cuatro de ellas desaparecieron de forma definitiva en este lapso de tiempo y nunca fueron reocupadas aunque, por supuesto, sus campos siguieron siendo trabajados.

Ni Ayerbe ni Montearagón fueron experimentos aislados en esta época: en los primeros meses de 1091, Sancho Ramírez fortificó un castillo llamado Superet Cesaraugustam, "Sobre Zaragoza", en la intersección de los valles del Jalón y el Ebro, y el documento que atestigua la consagración de la iglesia ya indica que, además de la "vieja paria", había otra, "nueva", reflejo de la sombría amenaza que la guarnición hacía pesar sobre las comunidades campesinas andalusíes de la zona. De hecho, los habitantes de este castrum tenían que pagar a la iglesia el diezmo de la parte correspondiente al rey del botín que consiguieran en sus algaria y azaria —del árabe andalusí algára y assaríyyah-, en ambos casos palabras que se refieren a la actuación de tropas ligeras que atacaban al enemigo y devastaban sus tierras. ${ }^{21}$ La misma actividad de saqueo desarrollaban los grupos caballerescos asentados en otros castillos como Arguedas, ${ }^{22}$ a poca distancia de

\footnotetext{
${ }^{16}$ DM. $\mathrm{n}^{\circ}$ 6. Este documento fue alterado en el siglo XII para fundir dos donaciones (y tal vez añadir fórmulas piadosas y otros detalles) del 5 de mayo de 1093 y del 13 de enero de 1090 o 1091 ("año IIII después que fue hecho y edificado Montearagón").

${ }^{17}$ Carballeire Debasa, Legados píos. El étimo en Corriente, Diccionario, s.v. "habiz".

${ }^{18}$ Laliena Corbera, "Repartos de tierras," 17-50, muestra que la distribución de bienes y rentas durante la conquista no tuvo nada de improvisada. También Sénac, Frontière, 449-74; Virgili, Ad detrimentum, 73-130. Para un periodo más tardío, Guichard, 451-71.

${ }^{19} \mathrm{CDPI} . \mathrm{n}^{\circ}$ 80: los lugares son: Tabernas, Sangarrén, Buñales, Torres de Violada, Vicién, Puivicién, Barbués, Pitillas, Torres de Barbués, Callén, Almudévar y Formiñena. Al año siguiente, Pedro l y el abad de San Juan de la Peña llegaron a un acuerdo para intercambiar algunas de estas fracciones de aldeas para unificar los derechos que poseían en cada una de ellas: CDPI. $n^{\circ} 98$ [1101.05].

${ }^{20}$ Prueba de la despoblación es que Alfonso I encargó a tres nobles de la Jacetania poblar Barbués en 1128: CDAI. $n^{\circ} 197 ; y$ Almudévar recibió carta de población en mayo de 1170 de Alfonso II: AllRA. $n^{\circ} 86$, sin que quedase ningún mudéjar por entonces. Torres de Violada, Pitillas, Puivicién y Formiñena dejan de ser mencionados en las fuentes como lugares habitados.

${ }^{21}$ DERRVE. $n^{\circ}$ 9. Los étimos en Corriente, Diccionario, s.v. "açaria" y "algara".

${ }^{22}$ La ocupación de Arguedas en abril de 1084 figura en unos anales de San Juan de la Peña insertos en la Crónica de San Juan de la Peña, 37.
} 
Tudela en la ribera navarra del Ebro; el Pueyo de Sancho, cerca de Barbastro; ${ }^{23}$ Juslibol, en las proximidades de Zaragoza y Gardeny, en las inmediaciones de Lleida. ${ }^{24}$ En este último caso, las madinas de Balaguer y Lleida estaban, de hecho, rodeadas de fortificaciones feudales, en particular las de Camarasa y Cubells, desde $1050 .^{25}$

$\mathrm{Al}$ sur del Ebro, la suerte a la que se enfrentaron las comunidades rurales musulmanas no fue muy diferente. En la amplia región que se extiende a lo largo de las faldas del Sistema Ibérico, las madinas - Calatayud, Daroca, Tarazona-, hasta entonces relativamente protegidas por Zaragoza y los husun que la rodeaban, cayeron en manos de Alfonso el Batallador con rapidez entre 1119 y 1120. Entre esta última fecha y 1124, el rey actuó en la zona que se extiende desde Cariñena hasta Monreal del Campo, de manera que el asentamiento de grupos de caballeros aragoneses que acompañaba a esta presencia fue crítico para las alquerías andalusíes de la región. Una de ellas era Almohada, citada una sola vez en las fuentes, como parte integrante del honor de Sancho Fortuñones Quadrat, en $1127 .{ }^{26}$ Situada en un punto estratégico, que domina una amplia plana llamada Campo Romanos desde sus poco más de $900 \mathrm{~m}$. de altitud, es también un núcleo interesante que sobrevuela el curso del río Huerva. El registro arqueológico de superficie muestra un lote de cerámicas comunes andalusíes que se puede fechar entre finales del siglo XI y principios del XII. ${ }^{27}$ La inexistencia de restos posteriores sugiere que la escueta referencia a la posesión de Quadrat sobre este lugar es un epitafio del poblamiento musulmán.

La fortificación de Monreal y Singra entre 1124 y 1128 supuso probablemente un trauma parecido para las decenas de alquerías de los somontanos de las Sierras Menera y de Albarracín. ${ }^{28}$ Bastará con recordar que la primera donación de Singra, efectuada por Alfonso I en favor de San Juan de la Peña en el primero de los años citado, agradecía el servicio prestado por el abad pinatense "quando ibi tenebamus fronteram", es decir, cuando estaba combatiendo en el entorno de Monreal, pues ese es el sentido de la expresión "frontera" en esta época. La segunda, cuatro años posterior, y esta vez en beneficio de la abadía de Montearagón, incluye el "castro qui ibi est" y manda al abad de esta canónica que la pueble lo antes que pueda "atque faciatis ibi bonam forsam et teneatis ibi fronteram ad honorem tocius christianitati" ${ }^{29}$ Estas primeras apariciones de la palabra "frontera" en textos latinos de este periodo tienen un contenido claramente bélico, como ha mostrado Philippe Sénac e indican una coyuntura militar concreta y, como en este caso, la existencia de castillos u otras fortificaciones. ${ }^{30}$ Entre los pequeños lugares que pudieron verse afectados por la presencia feudal en este territorio figura una alquería innominada, a la que designamos como "El Cabezo de la Cisterna" (Alba del Campo, prov. Teruel), excavada durante los tres últimos años. Se emplaza en lo alto de una colina escarpada y contaba

\footnotetext{
${ }^{23}$ CDPI. $n^{\circ} 63$ [1099.04].

${ }^{24}$ Juslibol: CDPI. $n^{\circ} 100$ [1101.07]; Gardeny: CDAI. $n^{\circ} 118$ [1123.02]

${ }^{25}$ Bofarull y Mascaró, Condes, 24-26 y CDSPA. $n^{\circ} 30$, un acuerdo sobre Camarasa entre Ramón Berenguer I y Arnau Mir de Tost, que evidencia los resultados de la violencia ejercida sobre los musulmanes de la región.

${ }^{26}$ DERRVE. $n^{\circ} 1151$. Sancho Fortuñones, con frecuencia citado por su apodo, era "zalmedina" de Zaragoza y, por tanto, uno de los nobles más cercanos a Alfonso I y más poderosos.

${ }^{27}$ Agradezco estas precisiones sobre la cerámica a Julián M. Ortega Ortega. Laliena Corbera, "Conquista feudal," 138-60 presenta un análisis más completo

${ }^{28} \mathrm{CDAl}$. $\mathrm{n}^{\circ} 132$ [1124] (donación a San Juan de la Peña, en la que se menciona Monreal).

${ }^{29} \mathrm{CDAl} . \mathrm{n}^{\circ} 201$ [1128.12] (la segunda donación de Singra). Se puede traducir por: "para que construyáis allí una buena fortificación y tengáis allí frontera para honor de toda la cristiandad".

${ }^{30}$ Sénac, "Frontera aragonesa," 151-66.
} 
con un torreón de cierto empaque; su origen data de algún momento del siglo XI y su final, también observado a través de las cerámicas obtenidas en estratigrafía, se sitúa a comienzos del siglo XII. El abandono coincide, por tanto, con la actividad armada cristiana y parece el resultado de una emigración organizada, no de un episodio de violencia. ${ }^{31}$

Algunos ejemplos, en absoluto los únicos, que muestran el despoblamiento de aldeas andalusíes en el Valle del Ebro no equivalen a una certeza, habrá que convenir en ello, puesto que la verificación de estas migraciones forzosas debe provenir de un programa de investigación bien articulado y, por ahora, los casos aislados solo evidencian la posibilidad de alcanzar resultados interesantes a nivel local. Sin embargo, es obvio que no avalan la hipótesis de que la conquista se saldó con la permanencia masiva de las poblaciones musulmanas, y, por tanto, que el desequilibrio demográfico en favor de los cristianos deba llevarse a una etapa muy posterior. ${ }^{32} \mathrm{Al}$ contrario: la arqueología - como los documentos, por otra parte- pone de relieve que los procesos posconquista fueron complejos y alejados de cualquier situación estática o de continuidad pura y simple.

Del mismo modo, valorar cuál fue la actitud de los conquistadores feudales es cuando menos complicado. Si los mecanismos de los que se valieron para imponer su dominio son discernibles, es bastante más difícil saber si los protagonistas eran conscientes de los resultados de sus opciones militares y políticas. En este sentido, la destrucción sistemática de la base fiscal de los estados taifas de Zaragoza, Lérida y Tortosa y la captación de esos recursos como botín condenó a la emigración a una parte importante de las poblaciones andalusíes, incluso si esa no era la voluntad de los feudales. La continuidad de bastantes comunidades campesinas andalusíes pegadas al terreno y a los terrazgos irrigados en los valles de los ríos Jalón, Jiloca, Aguasvivas y Martín, así como algunos lugares del Ebro medio y bajo, incrustadas en un enrevesado mosaico con los nuevos asentamientos cristianos, indica que, al igual que en las ciudades, hubo acuerdos locales que salvaguardaron la posesión de la tierra y el respeto por la religión de los vencidos, pero no una salvaguarda general.

Hay algunos testimonios significativos de estos pactos —además de las clásicas noticias sobre las que todos los historiadores insisten relativas a Tudela y Tortosa, que evocan a su vez los acuerdos de Zaragoza ${ }^{33}$ - que muestran como, además de extender una capa protectora sobre los mudéjares, tuvo lugar un elevado grado de violencia material y simbólica sobre ellos. Así, el convenio entre Ramón Berenguer IV y los musulmanes de Ascó, Flix, Móra d'Ebre, Garcia, Mazalefa, Castelló y Tivissa - que probablemente estaba interlineado en latín y árabe- les reconoce sus autoridades, leyes, castigos, derechos de herencia, religión, mezquitas y tierras. Pero algunas de las cláusulas dejan entrever la presión que padecen: así, los bailes condales deberán actuar como mediadores para recaudar los tributos que satisfacen con el fin de evitar arbitrariedades; se les asegura que los cristianos no entrarán por la fuerza en sus casas; obtienen garantías de que los "caballeros que están en los citados castillos" no podrán exigirles nada, incluyendo servicios de hueste; $\mathrm{y}$, por cerrar esta lista, sin agotarla, los moros cautivos de estos lugares que huyan de alguno de ellos, pueden refugiarse en otro y quedar, de este modo, libres. ${ }^{34}$ Una indicación según la

\footnotetext{
${ }^{31}$ Ortega Ortega, Dawla Raziniyya, 734-37, y comunicación personal.

${ }^{32}$ Es necesario señalar que, entre otros autores, Catlos, Victors, 92-106, sostiene con vigor la idea de una limitada emigración de los musulmanes.

${ }^{33}$ Tudela: CDAl. nº 91 [1119.03]; Tortosa: PACB. n 876 [1148.12]. Ferrer Mallol, "La capitulación," 269-80: capitulación de Borja.
} 
cual cada mudéjar debe responder únicamente por sus actos es interpretada por Josep María Font Rius a la luz de uno de los preceptos de la carta de Tortosa, menos de una década anterior, que ordena que "si los almorávides (almorabites) hicieran algún daño a los cristianos que estuvieran entre ellos o en sus tierras, no reciban por ello ningún mal los hombres de Tortosa", en referencia directa a los musulmanes. ${ }^{35}$

La amable lectura que muchos historiadores han realizado de estos documentos incide en la generosidad de Ramón Berenguer IV - y, antes que él, de Alfonso I- y, a lo sumo, en el interés "económico" de contener la fuga de mudéjares hacia al-Andalus, que, no obstante, está recogida en todos ellos: la emigración es un derecho que pueden ejercer sin restricción alguna $y$, en este documento en particular, con plena facilidad para abjurar del cristianismo, si se habían convertido. Sin embargo, una visión menos complaciente lleva a pensar que la experiencia anterior mostraba que para inmigrantes cristianos y mudéjares la frontera empezaba en la puerta de cada casa y que las agresiones individuales, las represalias colectivas y el maltrato de los intermediarios señoriales o las guarniciones castrales eran el contenido cotidiano de la diferencia étnica.

La crisis de la sociedad andalusí provocada por la conquista se saldó con una emigración generalizada, con independencia de que esta fuera o no la pretensión de la aristocracia feudal que la llevó a cabo; las poblaciones que permanecieron bajo la dominación cristiana cayeron de forma drástica en los centros urbanos y en grandes áreas rurales; las comunidades mudéjares que persistieron a lo largo de todo el periodo medieval fueron, como ha señalado con acierto Brian Catlos, el resultado de un amplio proceso de etnogénesis, en el que, además de un reagrupamiento geográfico, tuvieron que asimilar pautas culturales que, en principio, les eran ajenas, en especial en el terreno del poder y el control social. ${ }^{36}$

Desde la perspectiva de este trabajo - la frontera y el Estado feudal-, no cabe duda de que la demolición de los estados taifas del Valle del Ebro y de su herencia almorávide y, en paralelo, la devastación de la sociedad andalusí, fueron cruciales en la consolidación de los Estados feudales aragonés y catalán, unidos bajo el formato de la Corona de Aragón desde mediados del siglo XII. Sin embargo, más allá de los aspectos tradicionales tenidos en cuenta respecto a este proceso, tanto materiales - la alianza con las elites feudales y la redistribución de la riqueza - como ideológicos - la acumulación de carisma proveniente de la intensa difusión de la noción de guerra santa—, la relación entre la minoría mudéjar y el Estado jugó también un papel muy significativo en esa evolución institucional. Quizá por primera vez, el Estado - los reyes y sus oficiales, si se prefiere- se erigió en defensor de un grupo minoritario - $\mathrm{y}$ desvalido- dentro de la nueva sociedad feudal en vías de conformación en este territorio $\mathrm{y}$, al mismo tiempo, asumió el esencial deber ideológico - desde la perspectiva de sus súbditos cristianos- de velar para que la diversidad étnica fuese lo menos porosa posible. Todo ello daba al Estado un factor adicional de superioridad respecto a esas elites, una superioridad simbólica cuya importancia es difícil de exagerar.

\footnotetext{
${ }^{34}$ Font Rius, "Carta de seguridad," 260-83; Romero Tallafigo, "Relectura," 399-418.

${ }^{35}$ Font Rius, "Carta de seguridad," 268; la carta de Tortosa, ya citada, en PACB. $n^{\circ} 876$.

${ }^{36}$ Catlos, Victors, 390-408. En relación con la población musulmana de Tortosa, Virgili, "Campesinos," 25, afirma que "todos los indicios apuntan a una drástica reducción de sus efectivos, a pesar de desconocer los procedimientos empleados para llevarla a cabo."
} 


\section{La formación de grandes espacios señoriales en las fronteras de la Corona de Aragón}

La conquista del Valle del Ebro en la época de Alfonso el Batallador depositó en manos de un reducido grupo de nobles un poder territorial sin precedentes. Podemos obviar los casos de los magnates francos, como el conde Rotrou de Perche, que, de forma directa o a través de sus vasallos normandos, controló durante un decenio una extensa área alrededor de Tudela, ${ }^{37}$ porque su actividad o la de sus hombres no se prolongó más allá de la muerte del Batallador. Pero no los de algunos de los nobles aragoneses y navarros, que recibieron honores tan grandes en términos geográficos que apenas guardan parecido con los característicos y tradicionales de las regiones pirenaicas. Es lo que sucede con Fortún Garcés Cajal, que ostenta los principales honores de La Rioja desde que Alfonso I se apodera de la región en 1110 hasta la crisis del reino en 1134, y, lo que es más significativo para nuestras preocupaciones aquí, ejerce un poder indiscutido sobre un amplio sector de la frontera del Ebro desde Daroca a Monreal del Campo, transmitido en 1134 a su sobrino Sancho Î́niguez, que lo mantuvo en sus manos hasta $1169 .{ }^{38}$ Más al este, la cuenca del río Aguasvivas configuró también un inmenso honor cuyo centro estaba en Belchite, que fue gobernado por el noble Galindo Sánchez entre 1119 y 1128 . Su hermano Lope Sánchez lo sustituyó entre esta última fecha y 1148, mientras que su sobrino Galindo Jiménez prorrogó la impronta de este linaje en la comarca hasta 1174. Galindo Jiménez logró, además, sumar a sus posesiones el valle del Martín y dirigió sus ambiciones o las de sus vasallos hacia las sierras ibéricas, en particular la zona de Castellote. ${ }^{39}$

En tiempos del Batallador (+ 1134) y Ramón Berenguer III (+ 1131), estas serranías, así como los valles de los ríos Martín, Guadalope, Algás, la región de Lleida, el Camp de Tarragona y el Baix Ebre, estaban todavía en poder de los almorávides y, desde 1145, de los ra'is almohades levantinos, una situación que se prolongó hasta la caída de Tortosa y Lleida en 1148-1149. En esa coyuntura, los grandes nobles catalanes y aragoneses, con un apoyo circunstancial de Ramón Berenguer IV, habían comenzado a saquear respectivamente el Camp de Tarragona y el Bajo Aragón sin encontrar apenas resistencia. ${ }^{40}$ Un ejemplo sobresaliente de esta actividad es el de Robert Bordet, un caballero normando vinculado a Rotrou de Perche, presente en Tudela en los años 1120, que aceptó la infeudación que le hizo el arzobispo de Tarragona de esta ciudad y sus aledaños en 1129. Durante las siguientes dos décadas participó en la reorganización del Camp de Tarragona y gozó de una autoridad que, si bien permanece en una relativa oscuridad, no fue en modo alguno pequeña. A medio plazo, su relación con los prelados tarraconenses desembocó en agrios conflictos, a pesar de lo cual mantuvo en sus manos el poder local hasta su muerte en 1155 y sus descendientes aspiraron a continuar ejerciéndolo durante los años inmediatamente posteriores. ${ }^{41}$

\footnotetext{
${ }^{37}$ Laliena Corbera, "Larga stipendia," 149-69.

${ }^{38}$ Bishko, "Hispano-cluniac benefactor," 275-312, esp. 280-83.

${ }^{39}$ Sesma Muñoz, Utrilla Utrilla y Laliena Corbera, Agua y paisaje, 171-77.

${ }^{40} \mathrm{Flocel} \mathrm{Sabaté} \mathrm{insiste} \mathrm{también} \mathrm{en} \mathrm{el} \mathrm{desarrollo} \mathrm{señorial} \mathrm{en} \mathrm{la} \mathrm{frontera} \mathrm{catalana,} \mathrm{aunque} \mathrm{incide} \mathrm{sobre} \mathrm{todo} \mathrm{en} \mathrm{los} \mathrm{siglos} \mathrm{X} \mathrm{y}$ XI: "Frontière catalane," 205-9; "Occuper la frontière," 81-113.

${ }^{41}$ McCrank, "Norman Crusaders," 62-82. Durante los años 1150, hay varias cartas de población otorgadas por Robert o sus vasallos de acuerdo con los arzobispos: Tarragona [1149.02.9 y 09.3], Mangons [1149.04], La Buella [1150.03.7], Riudons [1151.01.25], Cambrils [1152.09.3 y 1154.09.14], Burgá [1157.04.1] y Salou [1157.07.14], en CPFC. nº 69, 73 y 74; 70; 80; 84; 91 y $96 ;$ y 105.
} 
El reparto de Tortosa después de la ocupación en 1148 revistió una complejidad considerable, puesto que, desde el principio, el Común de Génova y la orden del Temple tuvieron derechos adquiridos sobre fracciones importantes de la ciudad y su término. La retirada de los genoveses pocos años después aumentó la participación de Ramón Berenguer IV que, además, procuró premiar a Guillem Ramón de Montcada, el noble con el que se había comprometido de manera más firme en el curso de la conquista con rentas y no con territorios susceptibles de una transformación en señoríos. La excepción en este sentido, muy limitada, la constituyeron los macizos montañosos de Cardó, Sallent y La Fullola, de modo que es fácil concluir que, en esta región, el conde procuró evitar la formación de grandes áreas señoriales - con la única excepción de la orden del Hospital en Amposta y Ulldecona, que se inscriben en otro orden de cosas, como veremos. $^{42}$

En cambio, la conquista de Siurana y las Montañas de Prades desembocó en la aparición de otro de estos amplios espacios señoriales, regido por el linaje de los Castellvell, especialmente por Albert de Castellvell $(+1174)$. De su pariente Bertrán, afirmaba Ramón Berenguer que tenía en su nombre Siurana, y, en efecto, él y los miembros de su parentela controlaron la población de los principales lugares de la comarca, instalando inmigrantes a través de intermediarios señoriales que gestionaban estas operaciones a escala local. Siurana, Prades, Vilanova de Prades, Ulldemolins, Falset, Escornalbou y Morera figuran en la lista de núcleos que definen una extensa franja de la conquista realizada por los barones catalanes en los años $1150 .{ }^{43}$ El punto álgido de la implantación de los Castellvell en la región fue alcanzado cuando Alfonso II, en 1174, entregó como feudo a Guillem de Castellvell las localidades de Tivissa, Móra d'Ebre, Garcia y Marça, que se emplazan al sudoeste de los macizos de Siurana y se abren hacia el Ebro. Con esta decisión, Alfonso II pagaba 5.000 morabetinos que debía a Albert de Castellvell y que este había legado a su sobrino Guillem, así como la deuda contraída con Guillem por el servicio armado que había prestado al rey en Montpellier. ${ }^{44}$

Esta rápida enumeración no agota el catálogo de los distritos señoriales laicos forjados en tierras de conquista durante los años 1120-1170, pero sí manifiesta que se trata de un fenómeno a gran escala, que no ha recibido suficiente atención por parte de los historiadores. Esta carencia es muy visible en lo que afecta a las serranías ibéricas aragonesas, en relación con las cuales las fuentes son muy parcas. Allí, en los extremos de los enormes honores enumerados al principio, las campañas organizadas fueron la excepción y la depredación de baja intensidad, la norma. Bajo el mandato general de procurar el "bonum christianorum et destructionem sarracenorum", los pobladores de la frontera tenían libertad para emprender las cabalgadas que les pareciesen oportunas y retirar en ellas el botín adecuado. Así, a título de ejemplo de una fórmula que estimulaba este comportamiento, Alfonso II liberó a los monjes de la Sauve Majeure a los que había donado el castillo de Alcalá de la Selva y a los "pobladores vuestros que estén en la fortaleza (castro)" de darle el quinto de los rendimientos de las razias, excepto si eran el fruto de una

\footnotetext{
${ }^{42}$ Virgili, Ad detrimentum Yspanie, 73-102. También Shideler, Montcada, 183-95.

${ }^{43}$ Cf. CPFC. $n^{\circ}$ 95: Siurana, donde se menciona a Bertrán de Castellet [1153.04.29]; $n^{\circ}$ 95: Reus, aunque se trata de una sucinta noticia [1154.06.5]; $n^{\circ} 113$ : Prades, carta confirmada por Guillem y Albert de Castellet [1159.05]; $n^{\circ} 121$ : Vilanova de Prades, donde se cita a Albert como castlà de Siurana [1163.02.25]; $\mathrm{n}^{\circ}$ 128: Ulldemolins [1166.01.31]; $\mathrm{n}^{\circ}$ 133: Falset [1168.02]; $\mathrm{n}^{\circ}$ 138: Escornalbou [1170.12.8]; $\mathrm{n}^{\circ}$ 139: Morera, carta en la que Albert se titula dominus Siurane [1170.12.8]. Garí, Linaje de los Castellvell, 136-40 y 190-95. ${ }^{44}$ AllRA. $n^{\circ} 181$.
} 
convocatoria formal para el ejército del rey para atacar al-Andalus (“in Ispaniam”), ya que entonces los pobladores - pero no los monjes-debían entregárselo sin cometer fraude. ${ }^{45}$

En la misma línea, en noviembre de 1188, el canónigo Fortún Robert, en nombre del cabildo de la catedral de Zaragoza, situaba al frente de un lugar despoblado, Fuentespalda, en las tierras del Matarraña, a Arnal Bretón para que organizase la llegada de pobladores que, pasados cinco años, estaban obligados a prestar servicio armado con un caballero y un ballestero. Y añadía que "de los cautivos sarracenos y cristianos y de las cabalgadas contra los sarracenos, retengo la mitad de la quinta". 46 Al frente de estos grupos de pobladores bien armados y dispuestos a competir con ferocidad para apoderarse de las tierras de las comunidades andalusíes, que no contaban con el soporte de ninguna madina entre Albarracín y Tortosa - pero sí de algunos husun de primer orden-, estaban algunos nobles de segunda fila que fiaban su suerte y fortuna a su éxito en un espacio serrano en el que la presencia del rey fue episódica durante estos años. ${ }^{47}$ Uno de los casos más interesantes es el de Sancho de Tarazona, que, en 1163, hizo donación del castillo, la villa y la iglesia de Aliaga y otras aldeas menores cercanas al Hospital de San Juan de Jerusalén, sin que sepamos de dónde procedía este individuo que ostentaba la plena posesión señorial de una de las cuencas interiores de los macizos de la Sierra de Sant Just, entre los que se abre paso con dificultad el río Guadalope en su cabecera. ${ }^{48}$

Que estos verdaderos virreyes de la frontera y sus vasallos estaban en condiciones de competir con el estado feudal catalano-aragonés en la segunda mitad del siglo XII era una evidencia que no se ocultaba a los protagonistas. ${ }^{49}$ En este sentido, la mejor prueba es, sin duda, el notable triunfo de Pedro Ruiz de Azagra, un importante noble navarro procedente de un linaje con una sólida tradición de lucha contra el Islam. Entre 1164 y 1168, aplicó este celo a ayudar a Ibn Mardanis contra los almohades, lo que explica que este emir confiase en él para defender la frontera septentrional de su reino, sometida al duro castigo descrito en los párrafos precedentes. Para ello, le cedió la madina de Santa María de Albarración y el territorio que dependía de ella, que perdió con rapidez su población andalusí para recibir una oleada de inmigrantes navarros y aragoneses. Con el apoyo de Alfonso VIII de Castilla y de Sancho VI de Navarra, de quienes era vasallo directo, Pedro Ruiz dedicó su esfuerzo a consolidar lo que, desde cualquier punto de vista, era un principado autónomo desde 1170. La creación de un obispado en esta ciudad, camuflado como la restauración del visigodo de Segóbriga, sometido al arzobispo de Toledo y reconocido por el papado, constituyó un acierto que cegó las tentativas de Alfonso II, que había arrebatado el vecino altiplano de Teruel a Ibn Mardanis y asistía a esta evolución, amparada sobre todo por Castilla, impotente para expulsar a Pedro Ruiz de su flamante señorío. ${ }^{50}$ A pesar de que Albarracín quedó pronto limitado en sus posibilidades de expansión hacia Teruel y

\footnotetext{
${ }^{45}$ AIIRA. $n^{\circ} 163$.

${ }^{46}$ PCRA. $\mathrm{n}^{\circ} 127$

${ }^{47}$ Ortega Ortega, "Inestable frontera," 29-46.

${ }^{48}$ CEA. $n^{\circ} 2$. Es posible que fuese hijo de un Lope lbáñez de Tarazona que aparece en la documentación de Alfonso I en un par de ocasiones, una de ellas cuando recibió del rey Aliaga, Pitarque, Jarque de la Val y Alcalá, además de algún otro lugar: CDAl. $n^{\circ} 87$ [1118.12.18] y $n^{\circ} 122$ [1123]. Aunque así fuera, habría que explicar el modo en que había hecho efectiva una concesión 45 años anterior y con visos de ser un proyecto, no una realidad.

${ }^{49} \mathrm{El}$ mismo fenómeno se producía a comienzos del siglo XIII en las fronteras entre Castilla y León y Castilla-Navarra-Aragón, donde los grandes linajes de los Azagra, los Lara, los Haro y los Cameros construyeron dominios relativamente compactos que constituían la base de un poder aristocrático que manifiesta una conflictividad nada pequeña durante la primera mitad de esa centuria: Rodríguez López, Consolidación, 138-52, 197-254; Álvarez Borge, Cambios y alianzas.

${ }^{50}$ Almagro Basch, Señorío soberano.
} 
Cuenca, eso no resta un ápice al logro de esta magnate, capaz de jugar con tres soberanos para equilibrar su debilidad con la diplomacia y estabilizar su poder en esta parte de la frontera.

\section{Frontera, competencia aristocrática y Estado feudal}

Algunas decisiones de Ramón Berenguer IV y su entorno apuntan a que era consciente de la opresiva herencia que le había transmitido Alfonso el Batallador bajo la forma de estos grandes honores que mutaban con cierta rapidez hacia señoríos jurisdiccionales. $Y$, en consecuencia, del reducido campo que le dejaba para maniobrar un régimen feudal aragonés que primaba, por encima de todo, la heredabilidad de los honores. Un régimen que consagraba una amplia independencia de los barones que ostentaban estos dominios en la frontera meridional. ${ }^{51} \mathrm{La}$ introducción de las "costumbres de Barcelona" para las concesiones que efectuó a mediados del siglo XII en Aragón confirma que perseguía fórmulas para contener los daños que esta autonomía causaba a su propia autoridad. ${ }^{52}$ Pero la mejor comprobación de que exploraba alternativas distintas de la de dejar proseguir el engrandecimiento de un puñado de linajes señoriales, radica en la opción política de crear concejos de frontera para gestionar de manera eficaz y, hasta cierto punto, ajena a los nobles tenentes de los honores, la instalación de los nuevos pobladores y su nerviosa agitación contra los musulmanes. Así, el fuero de Daroca, cuya primera versión data de 1142 y coloca a esta localidad "in extremo sarracenorum", recoge una larga serie de normas consuetudinarias que muestran la formación de un concejo regido por jueces y alcaldes, con justicia propia y una solidaridad institucionalizada, que procuraba protección a las propiedades, defensa contra nobles agresivos y una relación distante respecto al rey. ${ }^{53}$ En este aspecto, indica que reserva al monarca el derecho a llamar a la hueste (fonsado) y la quinta parte del botín, compartida con el domino Daroce, el tenente del honor, "y esto tanto de los cautivos como del ganado y los paños de seda que no hubieran sido cortados con tijera. $Y$ si capturasen a un rey (sic), que lo entreguen al rey". Un concejo, por tanto, con una configuración semiurbana, provisto de milicias y con término en el que los límites meridionales apenas estaban apuntados pero llegaban probablemente hasta las crestas de las sierras ibéricas.

Con un criterio muy semejante, el conde otorgó una carta de población a Alcañiz en 1157, cuyos habitantes obtuvieron los fueros de Zaragoza sin mayores precisiones, que permitían a Ramón Berenguer IV conservar en sus manos el castillo y el honor, de acuerdo con el modelo aragonés. ${ }^{54}$ Los términos del nuevo concejo eran excepcionales:

\footnotetext{
${ }^{51}$ Un ejemplo: en 1143, dona a la orden del Hospital los castillos de Monzón, Mongai, Chalamera, Barberà, Remolinos y Corbins, rentas en Huesca, Zaragoza y el reino en general, el quinto de sus beneficios en las huestes contra los musulmanes, la décima parte de las conquistas que efectuase y "el honor de Lope Sánchez de Belchite, de la forma en que sobre esto pudiérais poneros de acuerdo con el citado Lope Sánchez". Es decir, dejaba al arbitrio de este noble la manera de hacer efectiva su donación, lo cual es un signo de su debilidad respecto a estos barones -PACB. $n^{\circ} 822$

${ }^{52}$ Adam J. Kosto sugiere que las "Costumbres de Barcelona" o Usatges tuvieron poco impacto real sobre el medio aristocrático catalán: Making Agreements, 279-81, pero esta idea contrasta con las decenas de concesiones efectuadas por Ramón Berenguer IV en tierras aragonesas con este régimen de posesión de las fortificaciones. La tenencia de los castillos era un aspecto crucial del poder, más allá de otros elementos ideológicos, sin duda importantes.

${ }^{53}$ Agudo Romeo, Fuero de Daroca, 37-53. Barrero García, Fuero de Teruel, 85, señala que la copia conservada inserta materiales procedentes de dos redacciones, hipótesis argumentada por M. M. Agudo que propone como segunda fecha ca. 1172 , en relación con la confirmación de Alfonso II: ibid. pp. 14-18. Basta con observar el tratamiento de "rey" que manifiestan estas normas para los dirigentes para comprobar que han sido remodeladas en un periodo posterior al gobierno de Ramón Berenguer IV.

${ }^{54}$ Laliena Corbera, "Carta de población," 253-67.
} 
todo el Bajo Aragón hasta las montañas ibéricas entre Benifassà y Morella, también con una precisión escasa, como correspondía a un territorio mal dominado. Como colectivo, los alcañizanos recibieron la posesión de aquellos castillos que poblasen con la obligación de cederlos al conde cuando este lo requiriese, es decir, como feudos en este caso según los Usatges.

El mapa dibujado por Enric Guinot en su libro sobre los límites del reino de Valencia es muy expresivo de lo que suponían estas dos regulaciones jurídicas de sendos concejos de frontera con los que Ramón Berenguer pretendía compaginar la persistencia de los honores con la formación de comunidades dotadas de compañías armadas separadas y distintas de las mesnadas de los nobles que tenían los honores. ${ }^{55}$ Permite comprobar que el hueco territorial que quedaba entre los territorios de ambos concejos correspondía al honor de Belchite, cuyo concejo careció, sin embargo, de la capacidad de crecimiento de los anteriores. Al mismo tiempo, muestra que el dispositivo lo completaba Tortosa, en una secuencia que comprendía desde la frontera con Castilla hasta el mar. Casi no hace falta decir que el conde barcelonés partía de un repertorio de experiencias gestadas desde finales del siglo XI en las extremaduras castellana, leonesa y navarro-aragonesa, que confluían en la formación de estos núcleos de vocación urbana y condensación institucional, tal y como ha mostrado, entre otros, José María Monsalvo. ${ }^{56}$

Estas experiencias no eran en absoluto incompatibles con la persistencia de un sistema de honores tradicional, en el que los magnates cobraban buena parte de las rentas atribuidas al rey - mercados, herbajes, derechos de alojamiento y probablemente los subsidios esporádicos de los que surgirán las futuras pechas en Aragón y las cuestias en Cataluña ${ }^{57}$ y se apropiaban de las dominicaturas reservadas en estas villas al soberano, pero perdían mucha de la preeminencia social que habían tenido medio siglo antes en localidades menores e incluso en las ciudades. De hecho, los primeros años del gobierno de Alfonso II manifiestan la extinción de algunos de estos linajes: en 1169 desaparece el último de los descendientes de Fortún Garcés Cajal, en 1174, el de Galindo Sánchez y, en la misma fecha, los Castellvell pierden a Albert de Castellvell, el gran señor de la época de Ramón Berenguer. Fueron sustituidos por otros, todavía sin estudiar, que recogieron el relevo de los linajes anteriores. En Aragón, Beltrán y Miguel de Santa Cruz se hicieron cargo del honor de Daroca (1175-1182) y de Teruel, un gran concejo de frontera desgajado de Daroca (1177-1185). Fernando Ruiz de Azagra, una vez que firmó la paz con Alfonso II, tuvo los honores de Calatayud (1188-1196), Daroca (1187-1196) y Teruel (1187-1196). Y, en Alcañiz, Artal de Alagón poseyó el honor hasta 1189, cuando la villa fue traspasada a la orden de Calatrava. ${ }^{58} \mathrm{~A}$ pesar de que estos personajes tuvieron un peso enorme en la curia alfonsina, la impresión es que la larguísima estabilidad que había caracterizado a la posesión de los honores en el ciclo anterior había cambiado. Esta impresión es todavía mayor en relación con el reinado de Pedro II, durante el cual las permutas en los honores parecen frecuentes, con una circulación rápida de los tenentes que figuran disfrutando de ellos. ${ }^{59}$ Las explicaciones para esta tendencia en los repartos de

\footnotetext{
${ }^{55}$ Guinot, Límits del regne, 14.

${ }^{56}$ Monsalvo Antón, "Frontera pionera," 45-126, con bibliografía. También Monsalvo Antón, "Alfoces regios," 29-100.

${ }^{57}$ Véase la querella entre Guillem Ramón de Montcada y Ramón Berenguer IV sobre la parte de las rentas de Tortosa que correspondía a cada uno, fechable entre 1153 y 1162: PACB. n 1096.

${ }^{58}$ Ubieto Arteta, "Tenentes".

${ }^{59}$ Véanse los cuadros de tenentes y honores que presenta Alvira Cabrer, Pedro el Católico, 2.414-2.426.
} 
honores pueden ser varias, y, al menos en tiempos de Pedro el Católico, no hay que descartar que los préstamos y la compensación por deudas influyesen, como ocurre en Cataluña, donde, en noviembre de 1209, Pedro II empeñó a Guillem de Cervera la bailía de Lérida y los dominios reales en La Litera, el Bajo Cinca (con Fraga y Mequinenza), el Baix Segre, Camarasa, Cubells, Castelldans y la Conca de Barberà para devolver un crédito de 21.500 morabetinos. ${ }^{60}$

Podría parecer que este creciente movimiento en los honores formaba parte de una estrategia para evitar la consolidación de linajes de prestigio en los de la frontera, pero no es en absoluto seguro, puesto que las dificultades económicas, las exigencias de las campañas bélicas y el juego de las facciones aristocráticas empujaron repetidamente a Alfonso II y Pedro II a claudicar ante algunos de estos magnates. Así, como consecuencia del citado traspaso de Alcañiz a los calatravos, el honor de esta villa, que había estado entre 11601163 y ca. 1176-1178 en poder de Palacín y su hijo Artal de Alagón, ${ }^{61}$ debió ser intercambiado por el señorío alodial de Calanda y Buñol (despoblado cerca de La Ginebrosa), un compacto espacio señorial que preludiaba las expectativas de Blasco de Alagón sobre Morella, una generación más tarde. ${ }^{62} \mathrm{El}$ mismo fenómeno se produjo también en la zona de Teruel, donde Berenguer de Entenza, que tuvo el honor de Teruel a principios de la década de 1170 -además de los de Calatayud en los años 1180 y Zaragoza, entre 1187 y 1193-, recibió la localidad de Manzanera en el extremo sur del reino en 1202, "ut popules et in eo fortitudinem facias ad deffensionem regni mei et sarracenorum confusionem", fortificación que debía tener según la Costumbre de Barcelona. ${ }^{63}$

\section{Una solución específica: la formación de señoríos de órdenes militares}

Sin embargo, la consolidación de las villas de frontera era un proceso relativamente lento, que requería la llegada de pobladores y el afianzamiento de su autonomía, algo nada sencillo, puesto que las redes clientelares de los barones citados se extendían también al tejido social de estas localidades. Esta es la razón por la cual Alfonso II optó por desencadenar una cascada de donaciones de señoríos en los territorios meridionales en favor de las instituciones eclesiásticas y, en particular, de las órdenes militares, a partir de 1174 (Tabla 1). ${ }^{64}$

La lista ha sido confeccionada con cierta arbitrariedad: abarca solamente el reinado de Alfonso II, comprende señoríos al sur del Ebro, pero no las localidades cuyas rentas eran asignadas a los templarios para cubrir los créditos captados por el monarca, y excluye también las donaciones de familias y heredades dispersas por la totalidad del territorio de la Corona. ${ }^{65}$ Puede parecer corta, pero algunos de estos señoríos eran muy grandes:

\footnotetext{
${ }^{60}$ Bisson, Fiscal Accounts, II, n 128. Sobre este personaje, Gonzalo i Bou y Salas i Flotats, "Guillem IV de Cervera," 405-18, con poca información sobre las posesiones señoriales de este linaje.

${ }^{61}$ Ubieto Arteta, "Tenentes".

${ }^{62}$ Hacia 1210, Blasco de Alagón heredó estos y otros señoríos en el centro del Valle del Ebro: Ubieto Artur, Nobiliario, 281. Buñol constituía aproximadamente la mitad del término de La Ginebrosa, en tanto que la otra mitad, que recibía el nombre de Camarón, retenida por el rey, acabó en manos de Arnal Palacín (primo de Blasco) y, finalmente, también en poder de Blasco: la donación de Pedro II, a costumbre de Barcelona, en PCRA. $\mathrm{n}^{\circ} 603$ [1206.03.21].

${ }^{63}$ Ubieto Arteta, "Tenentes" y PCRA. n 328 [1202.06.6].

${ }^{64} \mathrm{Al}$ referirnos a Alfonso II, como a cualquier otro soberano en este contexto, es necesario entender que sus actuaciones eran el resultado de estrategias que mezclaban su capacidad de decisión y los acuerdos o consejos de los miembros de una elite cortesana con múltiples ramificaciones.

${ }^{65}$ Las concesiones derivadas de las deudas de los sucesivos monarcas se concentraron en la orden del Temple y afectaron a algunos lugares del Bajo Ebro, después de atravesar una fase en la que los templarios disfrutaron de las rentas: Bisson,
} 
Tabla 1. Donaciones de señoríos en el sur de la Corona durante el reinado de Alfonso II (1174-1190).

\begin{tabular}{|c|c|c|c|}
\hline Beneficiario & Señorío & Fecha & Referencia AlIRA \\
\hline Selva Mayor & Alcalá de la Selva & $1174 / 02$ & 163 \\
\hline Temple & Horta de Sant Joan & $1174 / 06 / 30$ & 171 \\
\hline Conde Rodrigo & Alfambra & $1174 / 07$ & 173 \\
\hline Conde Rodrigo & Fuentes de Alfambra & $1175 / 02$ & 187 \\
\hline Monasterio Montearagón & Gúdar & $1175 / 02$ & 188 \\
\hline Temple & Encinacorba & $1175 / 07$ & 195 \\
\hline Obispo de Zaragoza & Valderrobres (Peña de Aznar Laganya) & $1175 / 07 / 24$ & 197 \\
\hline Hospital & Ulldecona & $1178 / 08$ & 260 \\
\hline Orden Calatrava & Alcañiz & $1179 / 03$ & 279 \\
\hline Hospital & Olocau & {$[1180 / 08]$} & 307 \\
\hline Hospital & Ulldecona & $1180 / 08 / 1$ & 308 \\
\hline Temple & Montornés & $1181 / 07 / 18$ & 328 \\
\hline Temple & Miravet y Riu d'Algars & $1182 / 03$ & 341 \\
\hline Conde Rodrigo & Orrios & $1182 / 03$ & 343 \\
\hline Monasterio Montearagón & Singra y Envidia & $1182 / 06$ & 353 \\
\hline Arzobispo Tarragona & Monroyo & $1185 / 10$ & 418 \\
\hline Orden Santo Redentor & Villel & $1187 / 12$ & 453 \\
\hline Temple & Polpís & $1190 / 01$ & 503 \\
\hline Hospital & Villarroya de los Pinares & $1190 / 12$ & 524 \\
\hline Hospital & La Barcella & $1192 / 10$ & 574 \\
\hline Temple & Villarluengo & 1194/01 & 600 \\
\hline Obispo Tarazona & Rubielos & $1194 / 06$ & 606 \\
\hline Hospital & Samper de Calanda & $1194 / 12$ & 628 \\
\hline Prior Tortosa & Benifassà, Fredes y Bel & $1195 / 04$ & 638 \\
\hline Obispo Zaragoza & Villacadima & $1195 / 05$ & 640 \\
\hline Monasterio Piedra & Piedra y Villar del Salz & $1195 / 05$ & 642 \\
\hline Arzobispo Tarragona & Monroyo & $1196 / 02$ & AHN. OOMM. carp. 434, $n^{\circ} 263$ \\
\hline
\end{tabular}

Alcañiz, Valderrobres, Monroyo y Castellote, por ejemplo, abarcaban la mayor parte del Bajo Aragón, con una treintena de villas y lugares. Lo mismo cabría decir de Horta y Ulldecona o de otros núcleos de la montaña turolense. Además, las cesiones de castillos del actual Maestrazgo, como Olocau y Montornés, todavía sin ocupar, apuntan a que la pauta de estos donativos no iba a interrumpirse mientras prosiguiera la conquista. Por otra parte, la cronología - que debe tener en cuenta los periodos en que Alfonso estuvo en el Midi francés - indica un programa bien definido y mantenido con firmeza a lo largo de dos décadas, que se extenderá también a la etapa del gobierno de Pedro II. Sobre la base de esta coherencia y de las declaraciones de las arengas de los documentos, que hacen referencia al "servicio del omnipotente Dios y todos los fieles cristianos y la expugnación de los paganos", 66 algunos autores han pensado que la explicación de estas donaciones radica en la necesidad de defender la frontera y sus vías de comunicación contra los almohades, que habían conseguido la sumisión de Valencia en el otoño de $1172 .{ }^{67}$

Sin perjuicio de que este argumento tenga sentido, no parece probable que el despliegue militar de las órdenes hiciera otra cosa que ratificar el compromiso armado de las milicias locales de los pobladores y, en todo caso, liderarlo. Tampoco tenemos clara la fecha de la incorporación de los comendadores a los diferentes dominios recibidos del rey. Por el contrario, la hipótesis que sostengo es que el objetivo de Alfonso II era vetar el acceso de los

Fiscal Accounts, 224 (Ascó), 227 (Riba-roja) y 228 (Seròs). Se trata de un fenómeno muy distinto de las donaciones efectuadas en las comarcas limítrofes con el Levante musulmán.

${ }^{66}$ AllRA. $n^{\circ} 173$. Alvira Cabrer, "Expresiones de la guerra santa," 127-54, señala con razón que estas expresiones están vin-

culadas sobre todo a los documentos concedidos a las órdenes militares.

${ }^{67}$ Ubieto Arteta, Historia de Aragón, 247-80. Guichard, Musulmans, 122-27, sobre el dominio almohade en Levante. 
grandes magnates a las tierras ocupadas hacia 1168-1170, una política deliberada de exclusión que pretendía evitar la formación de áreas señoriales poco permeables a la autoridad real, al estilo de Albarracín. En definitiva, eliminar la posibilidad de que la frontera avanzase de forma autónoma hacia la creación de señoríos competidores con el poder central. Para lograr este objetivo, la Iglesia y las órdenes eran un instrumento apropiado. Sus miembros se reclutaban entre las filas de la nobleza, pero en el proceso de integración en el ámbito eclesiástico eran sustraídos en gran medida de las redes de parentela y afinidad originales para pasar a sumarse a un colectivo cuya idiosincrasia incluía en particular la sumisión a la figura real. Los dirigentes de estas instituciones, obispos, arzobispos y maestres, tenían, en general, una relación especial con el soberano, que facilitaba el propósito del monarca y su círculo de consejeros, un grupo de nobles cuya personalidad e intereses habrá que estudiar con detenimiento en un futuro. Órdenes militares e instituciones eclesiásticas facilitaban un cierto repliegue de la gran nobleza laica en una fase crítica en la imposición de las estructuras estatales en los territorios meridionales de Aragón y Cataluña, tal y como habían quedado establecidos por la conquista entre 1148 y 1170.

\section{Conclusiones}

El objetivo de estas páginas es plantear la idea general de que la existencia de la frontera, como territorio intermedio en todos los sentidos - de dominación, de control social, de interacción cultural一, correspondió a un lapso de tiempo breve, puesto que supuso un desafío crucial para las estructuras del estado feudal catalano-aragonés del siglo XII. Los soberanos, en los que convencionalmente solemos centrar la esfera de decisión del poder en estos estados, y que, sin duda, tenían una significativa autonomía de actuación, patrocinaron la destrucción del grupo étnico formado por los musulmanes que padecieron la conquista y de los que solo una parte se integró en la sociedad feudal surgida de este proceso. Por otra parte, la formación de grandes señoríos en todo el Valle del Ebro, desde Tortosa hasta Albarracín, como hemos señalado en ocasiones, creó las condiciones para que pudiera producirse una hegemonía aristocrática en esta extensa región. Para contrarrestarla, Ramón Berenguer IV y Alfonso II promovieron la creación de grandes concejos dotados de jurisdicción sobre extensos espacios semipoblados. En una segunda fase, Alfonso y Pedro II multiplicaron las donaciones a las órdenes militares. Este fenómeno de donaciones a las órdenes no es exclusivo de la Corona aragonesa sino que es general a la Península y, por tanto, es una respuesta estructural a un problema central para los Estados feudales: liquidar la frontera como espacio susceptible de crear una sociedad y una configuración del poder capaces de evolucionar sin el Estado o, por decirlo de otra manera, sin la forma específica del Estado en esta época, el Estado feudal. Si en el transcurso de la primera etapa de la conquista la redistribución de la tierra y el botín para premiar y fortalecer la clase dirigente aristocrática había sido una condición sine qua non para consolidar los estados feudales aragonés y catalán, en la segunda, para proseguir esa dinámica, resultó imprescindible vigilar o, mejor, impedir, la instalación de los grandes linajes en las regiones arrebatadas a la taifa de Ibn Mardanis. La conquista de Valencia, en el primer tercio del siglo XIII, mostrará el grado de evidencia que esta política revestía para los dirigentes de la Corona. En otras palabras, la frontera era un proceso transitorio que no podía convertirse en indefinido sin quebrar la base del Estado feudal tal y como se estaba configurando en este periodo. 


\section{Agradecimientos}

Proyecto de Investigación MINECO ref. HAR2015-68209P. Grupo de Investigación de referencia CEMA, reconocido por el Gobierno de Aragón. Agradezco profundamente las observaciones de Julián Ortega Ortega y de los dos anónimos evaluadores que ha contribuido a mejorar este trabajo. Una primera versión de este trabajo fue presentada en el Seminario Internacional Las fronteras en la Edad Media Hispánica (siglos XIII-XVI), Sevilla, 24-28 de octubre de 2017.

\section{Disclosure statement}

No potential conflict of interest was reported by the author.

\section{Notes on contributor}

Carlos Laliena Corbera es Catedrático de Historia Medieval en la Universidad de Zaragoza. Dirige el Grupo de referencia de investigación CEMA. Autor de La formación del Estado feudal. Aragón y Navarra en la época de Pedro I, Huesca, 1996; Sistema social, estructura agraria y organización del poder en el Bajo Aragón en la Edad Media, Teruel, 1987 (2a ed. 2009), y Siervos medievales de Aragón y Navarra en los siglos XI-XIII, Zaragoza, 2012, además de un centenar y medio de artículos. Divide su investigación entre la historia social del poder en el periodo de expansión de las sociedades feudales (siglos XI-XIII) y las transformaciones económicas del reino de Aragón en la Baja Edad Media (siglos XIV-XV).

\section{References}

Fuentes primarias y abreviaturas

AHN. Archivo Histórico Nacional de Madrid.

AIRAII. Alfonso II, Rey de Aragón, Conde de Barcelona y Marqués de Provenza. Documentos (11621196), ed. Ana Isabel Sánchez Casabón. Zaragoza: Institución Fernando el Católico, 1995.

CDAI. Colección Diplomática de Alfonso I de Aragón y Pamplona (1104-1134), ed. José Ángel Lema Pueyo. San Sebastián: Eusko Ikaskuntza, 1990.

CDMSVS. Colección diplomática del monasterio de San Victorián de Sobrarbe (1000-1219), ed. J. Ángel Martín Duque. Zaragoza: Departamento de Historia Medieval, 2004.

CDPI. Colección Diplomática de Pedro I de Aragón y Navarra, ed. Antonio Ubieto Arteta. Zaragoza: Escuela de Estudios Medievales, 1951.

CDSPA. Col-lecció diplomàtica de Sant Pere d’Àger fins 1198, ed. Ramón Chesé Lapeña. Barcelona: Fundació Noguera, 2011.

CEA. Cartulario de la Encomienda de Aliaga, ed. León Esteban Mateo. Zaragoza: Anubar, 1979.

CPCF. Cartas de población y franquicia de Cataluña, ed. José María Font Rius. Madrid: Consejo Superior de Investigaciones Científicas, 1969-1983.

DERRVE. Documentos para el estudio de la reconquista y repoblación del Valle del Ebro, ed. José María Lacarra. Zaragoza: Anubar, 1982-1985.

DM. Documentos de Montearagón (1058-1205), ed. María Dolores Barrios Martínez. Huesca: Amigos del Castillo de Montearagón, 2004.

DSRI. Documentos correspondientes al reinado de Sancho Ramírez: documentos reales procedentes de la Real Casa y Monasterio de San Juan de la Peña, I, ed. José Salarrullana de Dios. Zaragoza: M. Escar, Tipógrafo, 1907.

PCAB. Els pergamins de l'Arxiu comtal de Barcelona, de Ramon Berenguer II a Ramón Berenguer IV. III-IV, ed. Ignasi J. Baiges et alii. Barcelona: Fundació Noguera, 2010.

PCRA. Pedro el Católico, rey de Aragón y conde de Barcelona (1196-1213). Documentos, testimonios $y$ memoria, ed. Martín Alvira Cabrer. Zaragoza: Institución Fernando el Católico, 2010. 


\section{Fuentes secundarias}

Abulafia, David, y Berend, Nora eds. Medieval Frontiers: Concepts and Practice. Abingdon y Nueva York: Routledge, 2002.

Agudo Romeo, María del Mar, ed. El Fuero de Daroca. Introducción, edición crítica, traducción, estudio léxico y concordancias . Zaragoza: Institución Fernando el Católico, 1992.

Almagro Basch, Martín. El señorío soberano de Albarracín bajo los Azagra. Historia de Albarracín y su Sierra. Teruel: Instituto de Estudios Turolenses, 1959.

Álvarez Borge, Ignacio. Cambios y alianzas. La política regia en la frontera del Ebro en el reinado de Alfonso VIII de Castilla (1158-1214). Madrid: Consejo Superior de Investigaciones Científicas, 2014.

Alvira Cabrer, Martín. "Expresiones de la guerra santa en las fuentes del reinado de Pedro el Católico, rey de Aragón y conde de Barcelona (1196-1213).” En Orígenes y desarrollo de la guerra santa en la Península Ibérica. Palabras e imágenes para una legitimación (siglos X$X I V$ ), ed. Carlos de Ayala Martínez, Patrick Henriet, y Santiago Palacios Ontalva: 127-154. Madrid: Casa de Velázquez, 2016.

Ayala, Carlos de, Pascal Buresi, y Philippe Josserand, eds. Identidad y representación de la frontera en la España medieval (siglos XI-XIV). Madrid: Collection de la Casa de Velázquez, 2001.

Barrero García, Ana María. El Fuero de Teruel. Su historia, proceso de formación y reconstrucción crítica de sus fuentes. Madrid: Instituto de Estudios Turolenses, 1979.

Barth, Fredrik, "Introducción." En: Los grupos étnicos y sus fronteras. La organización social de las diferencias culturales, ed. Fredrik Barth, 3ª ed., 9-48. México: Fondo de Cultura Económica, 1976.

Bartlett, Robert, y Angus MacKay. Medieval frontier societies. Oxford: Clarendon Press, 1996.

Bartlett, Robert. La formación de Europa. Conquista, colonización y cambio cultural, 950-1350. Valencia: Universidad de Valencia y Universidad de Granada, 2003.

Berend, Nora. "Medievalists and the Notion of the Frontier." The Medieval History Journal 2, no. 1 (1999): 55-72.

Bishko, Charles Julian. "The Castilian as Plainsman: The Medieval Ranching Frontier in La Mancha and Extremadura." En Charles J. Bishko. Studies in Medieval Spanish Frontier History. IV, 275312. Londres: Variorum Reprints, 1980.

Bishko, Charles Julian. "A hispano-cluniac benefactor in the epoch of navarro-aragonese separation: Fortún Garcés Cajal and the founding of San Adrián de Vadoluengo (Sangüesa). 1133-1145.” En Estudios en Homenaje a Don Claudio Sánchez Albornoz en sus 90 años. II. Anexos de Cuadernos de Historia de España, 275-312. Buenos Aires: Instituto de Historia de España, 1983.

Bisson, Thomas N. Fiscal Accounts of Catalonia under the Early Count-Kings (1151-1213). Berkeley y Londres: University of California Press, 1984.

Bofarull y Mascaró, Próspero. Los condes de Barcelona vindicados. Barcelona: Imprenta de J. Oliveres y Monmany, 1836, vol. II.

Bourdieu, Pierre. Sobre el Estado. Cursos en el Collège de France (1989-1992). Barcelona: Anagrama, 2014.

Buresi, Pascal. La Frontière entre chrétienté et Islam dans la péninsule Ibérique. Du Tage à la Sierra Morena (fin XIe-milieu XIIIe siècle). Paris: Éditions Publibook, 2004.

Burns, Robert I. The Crusader Kingdom of Valencia. Reconstruction of a Thirteenth-Century Frontier. Cambridge: Harvard University Press, 1967.

Carballeire Debasa, Ana María. Legados píos y fundaciones familiares en al-Andalus (siglos IX/X-VI/ XII). Madrid: Consejo Superior de Investigaciones Científicas, 2002.

Castrum 4. Frontière et peuplement dans le monde méditerranéen au Moyen Âge, ed. Jean-Marie Poisson. Roma y Madrid: Casa de Velázquez y École Française de Rome, 1992.

Catlos, Brian A. The Victors and the Vanquished. Christian and Muslims of Catalonia and Aragon, 1050-1300. Cambridge: Cambridge University Press, 2004.

Corriente, Federico. Diccionario de arabismos y voces afines en iberorromance. Madrid: Gredos, 1999.

Crónica de San Juan de la Peña (Versión aragonesa). Edición crítica, ed. Carmen Orcástegui Gros. Zaragoza: Institución Fernando el Católico, 1986.

Curta, Florin, ed. Borders, Barriers, and Ethnogenesis. Frontiers in Late Antiquity and the Middle Ages. Turnhout: Brepols, 2005. 
Ferrer Mallol, María Teresa. "La capitulación de Borja en 1122.” Aragón en la Edad Media 10-11 (1993): 269-280.

Font Rius, José María. "La carta de seguridad de Ramón Berenguer IV a las morerías de Ascó y Ribera del Ebro." En Homenaje a don José María Lacarra de Miguel en su jubilación del profesorado, I: 260-283. Zaragoza: Anubar, 1977.

Garí, Blanca. El linaje de los Castellvell en los siglos XI y XII. Bellaterra: Universidad Autónoma de Barcelona, 1985.

Gautier-Dalché, Jean. "Islam et Chrétienté en Espagne au XIIe siècle: contribution à l'étude de la notion de frontière". En Hesperis 46 (1959): 183-217.

González Jiménez, Manuel. "Frontier and Settlement in the Kingdom of Castile (1085-1350).” En Medieval Frontier Societies, ed R. Bartlett y Angus MacKay, 49-74. Oxford: Clarendon Press, 1996.

Gonzalo i Bou, Gener, y Manel Salas i Flotats. "Guillem IV de Cervera, cavaller i monjo de Poblet." En Anuario de Estudios Medievales 28 (1998): 405-418.

Guichard, Pierre. Les musulmans de Valence et la reconquête (XIe-XIIe siècles). Damasco: Institut Français de Damas, 1990-1991.

Guinot Rodríguez, Enric. Els limits del regne: el procés de formació territorial del País Valencià (1238-1500). Valencia: Institució Alfons el Magnànim, 1995.

Kosto, Adam J. Making Agreements in Medieval Catalonia. Power, Order, and the Written World, 1000-1200. Cambridge: Cambridge University Press, 2001.

Lacarra, José María. "Les villes-frontière dans l'Espagne des XIe-XIIe siècles". En Le Moyen Âge 75 (1963): 205-222.

Ladero Quesada, Miguel Ángel. "Sobre la evolución de las fronteras medievales hispánicas (siglos XI a XIV).” En Identidad y representación de la frontera en la España medieval (siglos XI-XIV), ed. Carlos de Ayala, Pascal Buresi y Philippe Josserand, 5-49. Madrid: Collection de la Casa de Velázquez, 2001.

Laliena Corbera, Carlos, "Regis fevales: la distribución de honores durante la conquista de Huesca, 1083-1104.” En Homenaje a don Antonio Durán Gudiol, 499-514. Huesca: Instituto de Estudios Altoaragoneses, 1995.

Laliena Corbera, Carlos. "La carta de población de Alcañiz de 1157." Studium. Revista de Humanidades 3 (Teruel, 1997): 253-267.

Laliena Corbera, Carlos. "La conquista feudal en el Valle Medio del Ebro: escenarios locales." En Balaguer, 1105. Cruïlla de civilitzacions, ed. Flocel Sabaté, 138-160. Lleida: Pagès Editors, 2007.

Laliena Corbera, Carlos. "Larga stipendia et optima praedia. Les nobles francos en Aragon au service d'Alphonse le Batailleur.” En Annales du Midi 112, no. 230 (2000): 149-169.

Laliena Corbera, Carlos. "Repartos de tierras en el transcurso de la conquista feudal del Valle del Ebro (1080-1160)." En Repartiments a la Corona d'Aragó (segles XII-XIII), ed. Enric Guinot y Josep Torró, 17-50. Valencia: Publicacions de l'Universitat de València, 2007.

Laliena Corbera, Carlos. La formación del Estado feudal. Aragón y Navarra en la época de Pedro I. Huesca: Instituto de Estudios Altoaragoneses, 1996.

Las sociedades de frontera en la España medieval. Zaragoza: Departamento de Historia Medieval, 1993.

Lieberman, Max. The Medieval March of Wales. The Creation and Perception of a Frontier, 10661283. Cambridge: Cambridge University Press, 2010.

MacKay, Angus. La España de la Edad Media. Desde la frontera hasta el Imperio, 1000-1500. Madrid: Cátedra, 1977.

Mann, Michael. Las fuentes del poder social. I. Una historia del poder desde los comienzos hasta 1760 d. C. Madrid: Alianza Editorial, 1991.

McCrank, Lawrence. "Norman Crusaders in the Catalan reconquiest: Robert Burdet and the principality of Tarragona, 1129-1155." Journal of Medieval History 7 (1981): 62-82.

Martínez Sopena, Pascual. "Las villas del rey y las fronteras del reino (ca.1158-1230)." En Construir la identidad en la Edad Media. Poder y memoria en la Castilla de los siglos VII a XV, ed. A. Jara Fuente, G. Martin e I. Alfonso Antón. 105-144. Cuenca: Universidad de Castilla La Mancha, 2010. 
Menjot, Denis. Murcie castillane. Un ville au temps de la frontière (1243-milieu du XVe siècle). Madrid: Casa de Velázquez, 2002.

Monsalvo Antón, José María. "De los alfoces regios al realengo concejil en el reino de León (11571230). La territorialidad de las ciudades y las villas reales entre la Cordillera Cantábrica y el Duero." En El reino de León en la época de las Cortes de Benavente, 29-100. Benavente: Centro de Estudios Benaventanos, 2002.

Monsalvo Antón, José María. "Frontera pionera, monarquía en expansión y formación de los concejos de villa y tierra. Relaciones de poder en el realengo concejil entre el Duero y el Tajo (c. 1072c. 1222)." Arqueología y Territorio Medieval 10, no. 2 (2003): 45-126.

Murray, Alan V., ed. The Clash of Cultures on the Medieval Baltic Frontier. Farnham: Routledge, 2009.

Ortega Ortega, Julián M. "Una inestable frontera feudal: el caso de Castellote (ca. 1150-1180)." Baylías, 7 (Centro de Estudios del Maestrazgo Turolense, 2010): 29-46.

Ortega Ortega, Julián M. La Dawla Raziniyya. Súbditos y soberanos en la taifa de Santa María de Oriente. Siglos V. H./XI d.C. Tesis doctoral inédita. Zaragoza, 2016.

Pastor de Togneri, Reyna. Del Islam al cristianismo. En las fronteras de dos formaciones económicosociales. Barcelona: Península, 1975.

Power, Daniel. The Norman Frontier in the Twelfth and Early Thirteenth Centuries. Cambridge: Cambridge University Press, 2004.

Power, Daniel. "Frontiers: Terms, Concepts, and the Historians of Medieval and Early Modern Europe." En Frontiers in Question. Eurasian Borderlands, 700-1700, ed. Daniel Power y Naomi Standen, 1-12. Basingstoke y New York: Palgrave Macmillan, 1999.

Power, Daniel, y Naomi Standen, eds. Frontiers in Question. Eurasian Borderlands, 700-1700. Basingstoke y New York: Palgrave Macmillan, 1999.

Rodríguez López, Ana. La consolidación territorial de la monarquía feudal castellana. Expansión y fronteras durante el reinado de Fernando III. Madrid: Consejo Superior de Investigaciones Científicas, 1994.

Romero Tallafigo, Manuel. "Una relectura de la carta de convenio y seguridad de Ramón Berenguer IV a las morerías de Tivissa y Mora (Tarragona) en la versión de la baronía de Entenza.” Historia. Instituciones. Documentos, 36 (2009): 399-418.

Sabaté i Curull, Flocel. El territori de la Catalunya medieval. Percepció de l'espai i divisió territorial al llarg de l'Edat Mitjana. Barcelona: Fundació Vives i Casajuana, 1997.

Sabaté, Flocel, "Frontera peninsular e identidad (siglos IX-XII)." Las Cinco Villas aragonesas en la Europa de los siglos XII y XIII, coord. Esteban Sarasa Sánchez, 44-97. Zaragoza: Institución Fernando el Católico, 2007.

Sabaté, Flocel. "Occuper la frontière du nord-est péninsulaire (Xe-XIIe siècles)." Entre Islam et Chrétienté. La territorialisation des frontières, XIe-XVIe siècle, dir. Stéphane Boisselier e Isabel Cristina Ferreira Fernandes, 81-113. Rennes: Presses Universitaires de Rennes, 2015.

Sabaté, Flocel. "Changement de frontières et perception de l'alterité en Catalogne (XIIe-XIVe siècle)." En Annexer? Les déplacements de frontières à la fin du Moyen Âge, ed. Stéphan Péquignot y Pierre Savy, 21-62. Rennes: Presses Universitaires de Rennes, 2016.

Sabaté, Flocel. "La frontière catalane (Xe-XIIe siècle): perception, alterité, pouvoir et mémoire." En Eriger et borner diòceses et principautés au Moyen Âge. Limites et frontières. II, ed. Baron Nacima, Stéphane Boisselier, Clément François, and Flocel Sabaté, 185-218. Villeneuve d'Asq: Presses Universitaires du Septentrion, 2017.

Sahlins, Peter. Boundaries: The Making of France and Spain in the Pyrenees. Berkeley, California, Oxford: University of California Press, 1989.

Scott, James C. The Art of Not Being Governed. An Anarchist History of Upland Southeast Asia. New Haven y Londres: Yale University Press, 2009.

Sénac, Philippe. "La frontera aragonesa en los siglos XI y XII. Pro defensionem christianorum et confusionem sarracenorum." Territorio, Sociedad y Poder 4 (2009): 151-166.

Sénac, Philippe. La Frontière et les hommes (VIIIe-XIIe siècle). Le peuplement musulman au nord de l'Ebre et les débuts de la reconquête aragonaise. Paris: Maisonneuve et Larose, 2000. 
Sesma Muñoz, José Ángel, Juan F. Utrilla Utrilla, y Carlos Laliena Corbera. Agua y paisaje social en el Aragón medieval. Los regadios del río Aguasvivas en la Edad Media. Zaragoza: Confederación Hidrográfica del Ebro, 2001.

Shideler, John C. Els Montcada: una familia de nobles catalans a l'Edat Mitjana (1000-1230). Barcelona: Edicions del 62, 1987.

Tomás Faci, Guillermo. "Derecho y fiscalidad en la formación de una frontera interna en la Corona de Aragón (Ribagorza, 1250-1300).” Hispania. Revista Española de Historia 71, no. 239 (2011): 615-638.

Torró, Josep. "Viure del botí. La frontera medieval com a parany historiogràfic." Recerques 43 (2001): 5-32.

Toubert, Pierre, "Frontière et frontières: un objet historique." En Castrum 4. Frontière et peuplement dans le monde méditerranéen au Moyen Âge, ed. Jean-Marie Poisson, 9-17. Roma y Madrid: Casa de Velázquez y École Française de Rome, 1992.

Ubieto Arteta, Agustín. Los “tenentes” en Aragón y Navarra en los siglos XI y XII. Valencia: Anubar, 1973.

Ubieto Arteta, Antonio. Historia de Aragón. La formación territorial. Zaragoza: Anubar, 1981.

Ubieto Artur, María Isabel, ed. Nobiliario de Aragón. Pedro Garcés de Cariñena; anotado por Zurita, Blancas y otros autores. Zaragoza: Anubar, 1983.

Virgili, Antoni. Ad detrimentum Yspanie. La conquesta de Turtusa i la formación de la sociedad feudal (1148-1200). Valencia: Publicacions de l'Universitat de València, 2001.

Virgili, Antonio. "Campesinos y renta feudal en una sociedad colonial en construcción. La región de Tortosa (1148-1212)". En la España Medieval 41 (2018): 23-48.

Weber, Max. Economía y sociedad. Esbozo de sociología comprensiva. $2^{\text {a }}$ ed. México: Fondo de Cultura Económica, 1964.

Zimmermann, Michel. "Le rôle de la frontière dans la formation de la Catalogne (IXe-XIIe siècle)." En Las sociedades de frontera en la España medieval, 7-29. Zaragoza: Universidad de Zaragoza, Departamento de Historia Medieval, 1993. 